\author{
コンピュータシミュレーションによる \\ 粉体および線材へのイオン注入分布の一般則* \\ 田原憧太郎*1 $\cdot$ 山本 幸男*1 $\cdot$ 荒川 正和*1 $\cdot$ 西城 理志*1 \\ 堀川 隼世*1 $\cdot$ 米田 知晃 $* 1$

\section{Universal Expression of Projected Range \\ Distributions for Spherical and Cylindrical Shape Target by Computer Simulation} \\ Shotaro TAWARA*1, Yukio YAMAMOTO*1, Masakazu ARAKAWA*1, Satoshi SAIJO*1, \\ Junsei HORIKAWA ${ }^{* 1}$ and Tomoaki YONEDA*1 \\ ${ }^{* 1}$ Department of Electrical and Electronics Engineering, National Institute of Technology, Fukui College, \\ Geshi-cho, Sabae-shi, Fukui 916-0064, Japan
}

(Received August 16, 2017, Accepted October 23, 2017)

\begin{abstract}
Ion implantation into microspheres and wires may open a new application field. Therefore, we extended the TRIM (Transport of Ions in Matter) code that simulates ion distributions for substrates to be applicable to spherical and cylindrical targets. Next, we fitted simulated profiles calculated by the TRIM code to the experimental ones to determine adequate parameters of electronic stopping powers. And, we simulated about various combinations to use the extended TRIM code which used parameters. Calculated projected ranges and implantation energies are reduced to modified reduced projected ranges and average reduced energy. Also, we derive the relations between the average reduced energy and the modified reduced projected ranges for spherical and cylindrical targets.
\end{abstract}

\section{1. はじめに}

イオン注入は半導体へのドーピング技術や金属の表面改質 技術として利用され ${ }^{1)}$, 近年は医用材料などの 3 次元形状に 対するイオン注入が新しい応用として期待されている2,3. このような基板材料以外への注入は, プラズマイオン注入 (PIII : Plasma Immersion Ion Implantation) ${ }^{2,3)}$ やターゲット フォルダ部分に回転機構など全方位注入となるような構造を 追加して一般的な注入装置を使用する方法 ${ }^{4-6)}$ が行われてい る. 一般的な注入装置を利用した粉体へのイオン注入として は, 癌治療に用いられるシリカ微小球へのPイオン注 入 $^{4,5)}$ ，医用材料や情報通信用材料への応用を目的とした金 属線やシリカファイバーへのイオン注入6) が報告されてい る.このため, 球状及び円柱状材料に対するイオン注入分布 を求めることは重要となってきている. 基板材料に対するイ オン注入分布は, TRIM (Transport of Ions in Matter) コー ド（現在は SRIM（Stopping Range In Matter）と呼ばれて いる）などのコンピュータシミュレーション 7,8), LSS (Lindhard-Sharff-Schiôtt）理論9,10)及びイオン注入の平均射影飛 程に対する一般則11,12)によって得ることができるが，基板試 料以外の形状に対しては計算することができない。そのた め, 我々は球状材料へのイオン注入シミュレーションを開発 し, 石英微小球へのPイオン注入に対する実験結果を正確 にシミュレートした ${ }^{13)}$.

本稿では, 同様の方法を用いて種々の実験データからシミ ュレーションで使用する電子阻止断面積を決定し, 球状材料

* 平成 29 年 8 月 17 日 第58回真空に関する連合講演会で発表

*1 福井工業高等専門学校 電気電子工学科 (下916-0064 福井県 鯖江市下司町)
および線状材料に対するイオン注入分布を計算した。 その計 算結果からイオン注入の平均射影飛程及び分散に対する一般 則を導出した.

\section{2. 電子阻止断面積の決定}

イオン注入において，エネルギーを持つ入射イオンは標的 原子に次々と衝突しエネルギーを失いながら進み, 最終的に は静止する.イオン注入に対するモンテカルロシミュレーシ ョンでは, 入射イオンと標的原子の 2 体衝突近似と電子阻 止断面積によるエネルギ一損失の計算から入射イオンの停止 位置が決をる. 統計誤差を小さくするために, 数万個のイオ ンの飛跡を追跡することにより, 注入分布を得る7,8). その ため, 計算に使用する阻止断面積の精度により, 得られる注 入分布の精度が決定する. 最もよく使用されているイオン注 入のシミュレーション・コードである TRIM コードにおい ても, バージョンアップにより実験データに一致するよう コード内の電子阻止断面積が修正されている ${ }^{14)}$. 本稿のシ ミュレーションで使用する入射イオン種に対する標的原子の 電子阻止断面積 $S_{e}\left(\mathrm{eV} \cdot 10^{15} \mathrm{~cm}^{2}\right)$ として Lindhard-Scharff の公式15)を用いた。

$$
\begin{aligned}
& S_{e}(E)=k E^{p} \\
& k_{L}=\frac{1.212 Z_{1}^{7 / 6} Z_{2}}{\left(Z_{1}^{2 / 3}+Z_{2}^{2 / 3}\right)^{3 / 2} M_{1}^{1 / 2}}
\end{aligned}
$$

ここで, $E, k, Z_{1}, M_{1}, Z_{2}$ は入射イオンのエネルギー，速度に 依存しない阻止パラメータ, 原子番号, 質量数, 標的原子の 原子番号を示し,$k / k_{L}$ は実験値に一致させるための補正項 である. 一般的には $k / k_{L}=1.5$ を使用するが，イオン種や標 


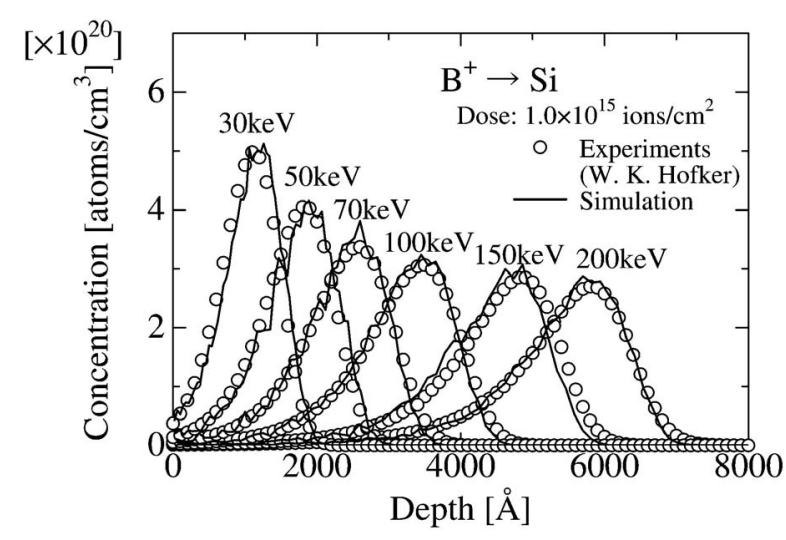

Fig. 1 Observed (SIMS : $\bigcirc$ ) and simulated (Present :-) depth profiles of $\mathrm{B}^{+}$implanted into Si with energies of 30-200 $\mathrm{keV}$. The $\mathrm{B}^{+}$doses are $1.0 \times 10^{15}$ ions $/ \mathrm{cm}^{2}$.

Table 1 Correction terms of electron stopping power for various ion and target combination.

\begin{tabular}{c|c|c|c|c}
\hline \hline Projected atom & Target atom & $k / k_{\mathrm{L}}$ & $\mathrm{p}$ & Exp. data \\
\hline $\mathrm{B}$ & $\mathrm{O}$ & 0.60 & 0.5 & Ref. 16 \\
\hline $\mathrm{B}$ & $\mathrm{Si}$ & 1.55 & 0.5 & Ref. 17 \\
\hline $\mathrm{B}$ & $\mathrm{C}$ & 0.90 & 0.5 & Ref. 18 \\
\hline $\mathrm{O}$ & $\mathrm{Si}$ & 1.30 & 0.5 & Ref. 14 \\
\hline $\mathrm{O}$ & $\mathrm{O}$ & 1.00 & 0.5 & Ref. 14 \\
\hline $\mathrm{Al}$ & $\mathrm{Si}$ & 0.90 & 0.5 & Ref. 19 \\
\hline $\mathrm{P}$ & $\mathrm{O}$ & 0.60 & 0.5 & Ref. 13 \\
\hline $\mathrm{P}$ & $\mathrm{Si}$ & 1.50 & 0.5 & Ref. 13 \\
\hline $\mathrm{S}$ & $\mathrm{Si}$ & 1.60 & 0.5 & Ref. 20 \\
\hline $\mathrm{Cr}$ & $\mathrm{Si}$ & 1.50 & 0.5 & Ref. 21 \\
\hline
\end{tabular}

的材料の種類によって適切な值を選択する. $E^{p}$ に抢ける幕 指数 $p$ は Lindhard-Scharffの公式では $p=0.5$ と示される が，実験值に一致させるためにべき乗則近似として $p$ で調整 する場合もある，このため，実験結果として報告されている 様々なイオン注入分布13,14,16-21) とイオン注入シミュレーショ ンによる計算結果を比較することでLindhard-Scharff の電 子阻止断面積に打汀補正項を決定した。 $30-200 \mathrm{keV}$ の $\mathrm{B}^{+}$イオンを $\mathrm{Si}$ に $1.0 \times 10^{15} \mathrm{ions} / \mathrm{cm}^{2}$ イオン注入した試料の SIMS (二次イオン質量分析法) の測定結果17) と最適な電子 阻止断面積を使用したシミュレーションの結果を Fig. 1 に 示す.ベストフィットした阻止断面積の補正項 $k / k_{L}$ と $p$ の 值はそれぞれ 1.55 と0.5である。同様の方法で決定した $\mathrm{B}^{+}$, $\mathrm{O}^{+}, \mathrm{Al}^{+}, \mathrm{P}^{+}, \mathrm{Cr}^{+}, \mathrm{S}^{+}$の $\mathrm{Si}, \mathrm{O}, \mathrm{C}$ に対する電子阻止断面積の 補正項を Table 1 に示す. 今回の組み合わせにおいて $p=$ 0.5 とした.

\section{3. 粉体および線材へのイオン注入}

TRIM などのシミュレーション・コードは基板に対する イオン注入シミュレーションであり, 粉体（微小球）などの 球形試料やファイバーなどの線状試料には対応していない.

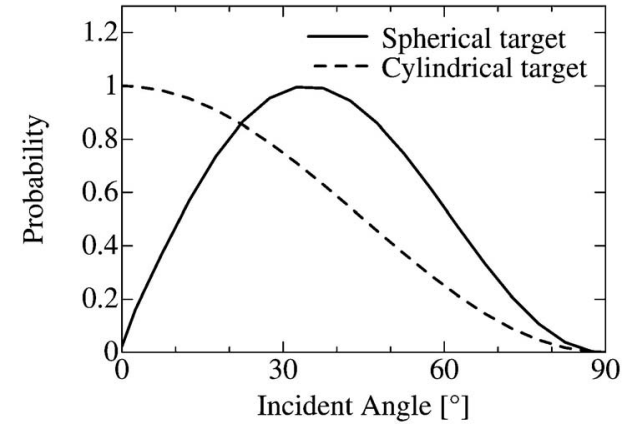

Fig. 2 Probability distribution of incident angle for spherical and cylindrical shape target.

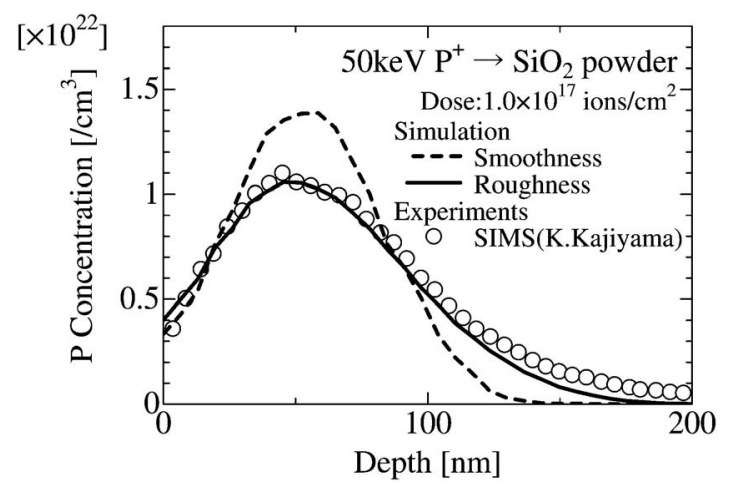

Fig. 3 Observed ${ }^{2)}$ (SIMS : $\left.\bigcirc\right)$ and simulated (-) depth profiles of $50 \mathrm{keV} \mathrm{P}{ }^{+}$implanted into $\mathrm{SiO}_{2}$ glass microspheres for doses of $1.0 \times 10^{17}$ ions $/ \mathrm{cm}^{2}$.

これらの形状の試料へのイオン注入分布を計算する場合に は, ビームの入射方向に対する試料表面の角度を考慮する必 要がある. 球形試料や線状試料に対して, 全方位からイオン 注入が行われると仮定し，ピーク值の確率が 1 となるよう に規格化した Fig. 2 の分布に従って入射角度を計算した。

K. Kajiyama が行った $25 \mu \mathrm{m} \phi$ の石英微小球へのP イオン 注入では, 微小球の全面に一様に注入されるように試料室を 振動してかき混ぜている5 . Fig. 3 に SIMS の測定結果と微 小球（真球の場合と表面ラフネスを仮定した場合）に対する イオン注入のシミュレーション結果を示す. 真球に対するシ ミュレーション結果とSIMS の測定結果は, Pのピーク位 置の点では一致するが，Pが深い位置まで分布している点で は一致しない13)。注入に用いた試料は溶融した合成石英の 空中噴射で作成している. しかし, イオン注入した試料の表 面は SIMS 測定のビーム径 $(0.5 \mu \mathrm{m} \phi)$ に対して十分に平坦 でない，そのため，平坦な表面を仮定した場合のシミュレー ションとは一致しないが, 微小球の表面粗さを考慮すること で分布をシミュレートすることができる.

K. Kajiyama が行った $75 \mu \mathrm{m} \phi$ のシリカ $\left(\mathrm{SiO}_{2}\right)$ ファイバー 抢よび $200 \mu \mathrm{m} \phi$ の $\mathrm{Al}$ 線への B イオン注入では, 表面に対し て均一に注入されるようにイオンビームに対して垂直に設置 された線状試料が一様回転している6). Fig. 4 にシリカファ イバーと $\mathrm{Al}$ 線への B イオン注入の SIMS の測定結果と線材 （表面が平坦の場合と表面粗さを仮定した場合）に対するイ オン注入のシミュレーション結果を示す. $\mathrm{SiO}_{2}$ ファイバー 


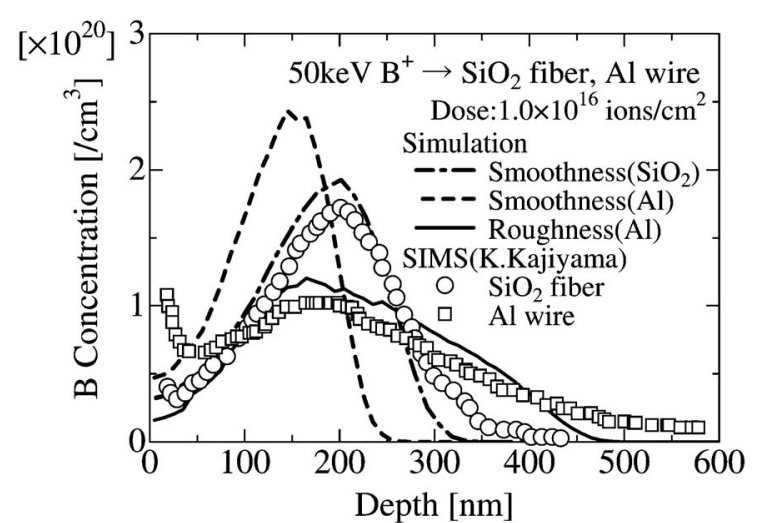

Fig. 4 Observed $^{3)}($ SIMS : $\bigcirc)$ and simulated (-) depth profiles of $50 \mathrm{keV} \mathrm{B}{ }^{+}$implanted into $\mathrm{SiO}_{2}$ fiber and $\mathrm{Al}$ wire for doses of $1.0 \times 10^{16} \mathrm{ions} / \mathrm{cm}^{2}$.

の結果は良い一致を示すが，Al 線の SIMS 測定結果は非常 に幅広い分布を示し，十分な一致を示さない。このため， $\mathrm{Al}$ 線について Fig. 4 に示すように表面粗さを仮定する必要 がある.

\section{4. 無次元化した平均射影飛程の一般化式}

Table 1 に示した入射イオンとターゲット元素の組み合わ せについて, 球状及び円柱状材料へのイオン注入分布をコン ピュータシミュレーションで計算し，その結果から平均射影 飛程 $R_{p}$ を求めた。本稿に扔いて以下に示す注入イオン種, ターゲット種, エネルギー $E$ 及び平均射影飛程 $R_{p}$ を用いて 無次元化した平均還元エネルギー $\varepsilon_{A V}$ 及び修正還元平均射影 飛程 $\rho_{M P}{ }^{12)}$ を用いて，粉体および線材に対する簡単な関保式 を導出した。

$$
\begin{aligned}
& \varepsilon_{A V}=\sum_{i=1}^{n} \frac{a_{i}}{Z_{1} Z_{i} e^{2}} \frac{M_{i}}{M_{1}+M_{i}} C_{i} E, a_{i}=\frac{0.88534 \alpha_{0}}{\left(Z_{1}{ }^{1 / 2}+Z_{i}{ }^{1 / 2}\right)^{2 / 3}} \\
& \rho_{M P}=n \sum_{i=1}^{n} \pi N_{i} a_{i}{ }^{2} C_{i} \frac{4 M_{1} M_{i}}{\left(M_{1}+M_{i}\right)^{2}}\left(\frac{Z_{i}}{Z_{1}}\right)^{\alpha} R_{p}, \\
& \alpha=\left\{\begin{array}{cc}
0.54 & \left(Z_{1}<Z_{i}\right) \\
0 & \left(Z_{1}>Z_{i}\right)
\end{array}\right.
\end{aligned}
$$

ここで, $Z_{i}, M_{i}, \quad C_{i}, \quad a_{i}$ は多元素で構成される標的材料の $i$ 番目の元素の原子番号, 質量数, 組成比, 遮蔽半径であり, $n$ は標的材料に含まれる元素の総数である. また, $N_{i}$ は標 的材料の原子数密度に組成比 $C_{i}$ をかけたものである. さら に， $\alpha$ は補正項である. 前述した式に従って粉体へのイオン 注入に対する平均還元エネルギー及び平均還元飛程を Fig. 5 に示す.この結果から, 最小二乗法を用いた近似式として, $\rho_{M p}=1.29 \varepsilon_{A V}$ の関係式が得られた. 一方, Fig. 6 に示す線 材に対しては $\rho_{M p}=1.43 \varepsilon_{A V}$ の関係式が得られた。これらの 関係式の誤差はそれぞれ $11 \%$ と $12 \%$ である。

\section{5. まと め}

我々が開発した球状材料抢よび線状材料に対するイオン注 入シミュレーションによる計算結果が実験結果と比較し, 良 い一致を得ることができた。 また, 決定した粉体及び線材に

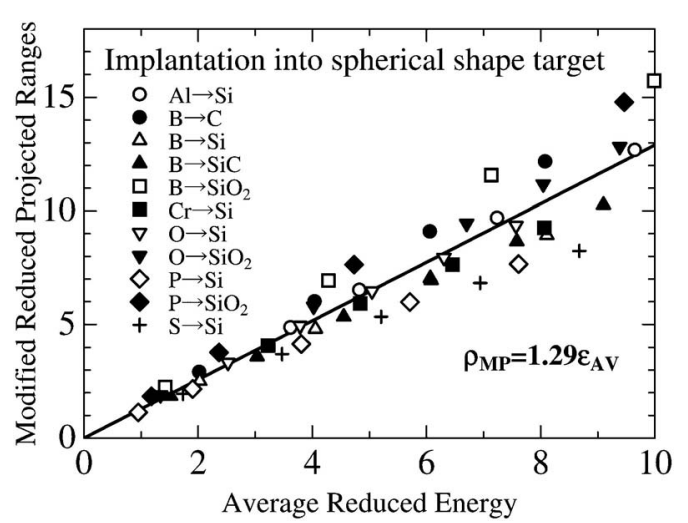

Fig. 5 Universal expression of projected ranges in spherical shape targets.

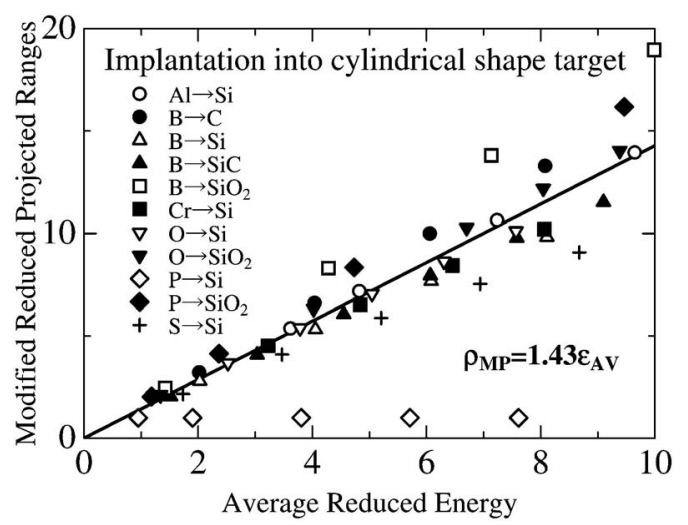

Fig. 6 Universal expression of projected ranges in cylindrical shape targets.

対する平均射影飛程の一般則の誤差はそれぞれ $11 \%$ と $12 \%$ であり, 粉体や線材などへのイオン注入時の分布を簡易的に 得ることができることを示した. 一方, 低エネルギー時の弾 性散乱によるエネルギー損失や高エネルギー時の電子阻止断 面積については, 今回の補正項だけでは十分な精度が出ない ため修正が必要である.

\section{謝辞}

本研究において多くのご指導を賜った梶山健二博士抢よび イオン工学センターのスタッフに感謝いたします.

\section{[文献〕}

1) J. F. Ziegler: Ion Implantation, Science and Technology 2nd edition (Academic Press, Orlando, Florida, 2012).

2) M. M. M. Bilek: Appl. Surf. Sci., 310 (2014) 3.

3) J. R. Conrad, J. L. Radtke, R. A. Dodd, F. J. Worzala and N. C. Tran: J. Appl. Phys., 62 (1987) 4591.

4) M. Kawashita, F. Miyaji, T. Kokubo, G. H. Takaoka, I. Yamada, Y. Suzuki and K. Kajiyama: Nucl. Instrum. Methods Phys. Res. B, 121 (1997) 323.

5) K. Kajiyama, Y. Suzuki, M. Inoue, T. Kokubo, M. Kawashita and F. Miyaji: Proc. of 11th Int. Conf. Ion Imp. Tech., Austin, Texas, 1995,816 .

6) K. Kajiyama, K. Sekine, T. Yoneda, T. Shibauchi and M. Yamamoto: Proc of 12th Int. Conf. Ion Imp. Tech., Kyoto, Japan, 1998, 982. 
7) J. P. Biersack and L. G. Haggmark: Nucl. Instrum. Methods, 174 (1980) 257.

8) J. F. Ziegler, J. P. Biersack and U. Littmark: The stopping Power and Range of Ion in Solids (Pergmon, New York, 1985).

9) J. Lindhard, M. Sharff and H. E. Schiôtt: Mat. Fys. Medd. Dan. Vid. Selsk., 33 (1963) 14.

10) J. F. Gibbons and S. Mylorie: Appl. Phys. Lett., 22 (1973) 568.

11) S. Kalbitzer and H. Oetzmann: Radiat. Eff., 47 (1980) 57.

12) Y. Kido and J. Kawamoto: Appl. Phys. Lett., 48 (1986) 257.

13) T. Yoneda: J. Vac. Soc. Jpn., 52 (2009) 124.

14) T. Yoneda, K. Kajiyama, F. Tohjou, Y. Yoshioka, A. Ikeda, Y.
Kisaka, T. Nishimaru and Y. Kido: Jpn. J. Appl. Phys., 36 (1997) 7323.

15) J. Lindhard and M. Sharff: Phys., Rev., 124 (1961) 128.

16) J. H. Liang: Nucl. Instrum. Methods Phys. Res. B, 180 (2001) 216.

17) W. K. Hofker: Philips Res. Rep., 8 (1975) 1.

18) M. S. Janson, M. K. Linnarsson, A. Hallén and B. G. Svensson: J. Appl. Phys., 93 (2003) 8903.

19) R. G. Wilson: J. Appl. Phys., 60 (1986) 2797.

20) R. G. Wilson: J. Appl. Phys., 55 (1984) 3490.

21) R. G. Wilson: J. Appl. Phys., 52 (1981) 3954. 